\title{
Conservatively managed spontaneous chylous ascites in a non alcoholic cirrhotic patient - case report and literature review
}

\author{
${ }^{1}$ Anne D. D. Joseph, ${ }^{1}$ Vathulan Sujanitha, ${ }^{1}$ Kumanan $T$ \\ ${ }^{1}$ University Medical Unit, Teaching Hospital Jaffna, Sri Lanka.
}

\begin{abstract}
Chylous ascites is characterised by the accumulation of lymphatic fluid in the peritoneal cavity. It is a rare presentation of liver cirrhosis; it can be the initial presentation or can occur in the course of the disease. Although in developing countries the main causes were tuberculosis and filariasis, this is the case of chylous ascites due to non alcoholic liver cirrhosis. In the present case the chylous ascites was an incidental finding, and it was well responded to initial conservative management. With the next six months of follow up it was noted that the patient was in remission. This case showed that if there is no great suspicion of malignancy the invasive diagnostic investigations are not needed and treating the underlying condition is the crucial step in the management.
\end{abstract}

\section{Key words}

chylous ascites, spontaneous, cirrhosis, nonalcoholic.

\section{Introduction}

Chylous ascites (CA) is an uncommon form of peritoneal fluid characterized by free, triglyceride rich, milky intestinal lymph in the peritoneal cavity. It can occur in paediatric as well as in adult population (1). In adults the causes of CA can be divided as traumatic and atraumatic. Common causes of traumatic CA include postsurgical, radiotherapy, blunt and penetrating abdominal trauma (1). Lymphatic anomalies, malignancy (25\%), mycobacterium infections, liver cirrhosis, filariasis, inflammatory causes such as pancreatitis, retroperitoneal fibrosis and systemic lupus erythematosus are leading causes of atraumatic $\mathrm{CA}(1,2)$. Although the real incidence of CA is not clearly understood, the reported incidence of it is approximately 1 in 20,000 admissions at a large university-based hospital over 20 -year period (3). CA due to liver cirrhosis accounts for $0.5 \%$ to $1.0 \%(4,5)$.

Here we present the first report of chylous ascites from Sri Lanka, where the CA was an incidental finding in a patient and diagnosed as having nonalcoholic liver cell disease on further evaluation.

\section{Case report}

A 66-year-old male, known to have type 2 diabetes mellitus, hypertension and coronary artery disease for ten years; presented with a history of right side painless scrotal swelling over three weeks duration. He had abdominal bloating over the same period, but he didn't have weight loss, fever, abdominal pain, constipation, haematemesis, ankle oedema or altered sleep pattern. He was a non-smoker and non-alcoholic. He underwent coronary artery bypass graft five years back and otherwise leading a healthy life.

On clinical examination he was afebrile; not pale or icteric; no ankle oedema and had a normal sensorium. He was averagely built; his vital clinical parameters were stable. Cardiovascular, 
respiratory and neurological examinations were unremarkable. Abdominal examination revealed distended abdomen, gross ascites with fluid thrill and right sided hydrocele. No organomegaly was appreciated.

Baseline investigations including liver biochemistry were normal, summarized in table 1 .

Table. 1. Baseline investigation of the patient

\begin{tabular}{|c|c|c|}
\hline Investigations & Results & Ref. Range \\
\hline White blood cells $/ \mathrm{mm}^{3}$ & 9150 & $4000-100000$ \\
\hline Neutrophils (\%) & 69.0 & $40-80$ \\
\hline Lymphocytes (\%) & 28.0 & $20-40$ \\
\hline Haemoglobin $(\mathrm{g} / \mathrm{dL})$ & 13.3 & $12-16$ \\
\hline $\begin{array}{l}\text { Mean corpuscular volume } \\
\text { (fL) }\end{array}$ & 94.2 & $80-100$ \\
\hline Platelets $/ \mathrm{mm}^{3}$ & 246000 & $\begin{array}{l}(150- \\
410) \times 10^{3}\end{array}$ \\
\hline $\begin{array}{l}\text { Erythrocyte sediment rate } \\
\left(\mathrm{mm} / 1^{\text {st }} \text { hour) }\right.\end{array}$ & 17 & $10-15$ \\
\hline $\begin{array}{l}\text { C-Reactive protein } \\
(\mathrm{mg} / \mathrm{L})\end{array}$ & 2.2 & $0-3$ \\
\hline $\begin{array}{l}\text { Fasting blood sugar (mg/ } \\
\text { dL) }\end{array}$ & 110 & $80-130$ \\
\hline $\begin{array}{l}\text { Alanin transaminase } \\
(\mathrm{U} / \mathrm{L})\end{array}$ & 52 & $16-63$ \\
\hline $\begin{array}{l}\text { Aspartate transaminase } \\
(\mathrm{U} / \mathrm{L})\end{array}$ & 42 & $15-37$ \\
\hline $\begin{array}{l}\text { Alkaline phosphatase } \\
\text { (IU/L) }\end{array}$ & 74 & 44- 147 \\
\hline Total Bilirubin $(\mu \mathrm{mol} / \mathrm{L})$ & 6.8 & $0-17.1$ \\
\hline Total protein $(\mathrm{g} / \mathrm{L})$ & 75 & $64-82$ \\
\hline Albumin $(\mathrm{g} / \mathrm{L})$ & 34 & $34-50$ \\
\hline Blood urea (mmol/L) & 4.3 & $2.5-6.4$ \\
\hline PT/INR & $13 \mathrm{~s} / 1.08$ & $\begin{array}{l}10-13 \mathrm{~s} / 0.8- \\
1.2\end{array}$ \\
\hline APTT & $34 \mathrm{~s}$ & $24-36 s$ \\
\hline
\end{tabular}

Ultrasonography of the abdomen confirmed the presence of gross ascites with coarse echoic pattern of the liver favoring a chronic liver cell disease; portal vein and spleen were normal, and right side hydrocele was noted. Abdominal paracentesis was done, and four liters of milky white ascitic fluid was drained (figure.1).
Figure. 1. Milky white chylous ascitic fluid obtained from the abdominal paracentesis

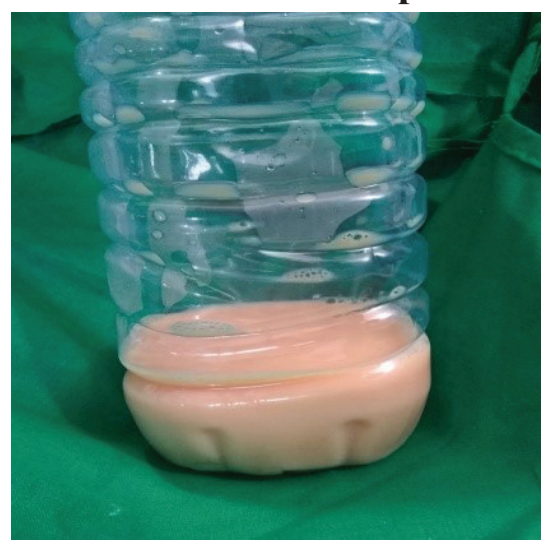

On subjecting the fluid for the analysis, it showed the following results. (Table 2) Ascitic fluid analysis confirmed that was chylous ascites. Further investigations were done to exclude the other common causes of chylous ascites. Prostate specific antigen, cancer antigen 19-9, alfa-foetoprotein, anti nuclear antibody, filarial antigen, Hepatitis B surface antigen, Hepatitis C Antibodies and retroviral screening were negative. Contrast enhanced computer tomography (CT) of chest, abdomen and pelvis revealed presence of moderate ascites and features of chronic liver cell disease.

\section{Table. 2. Analysis of the ascitic fluid.}

\begin{tabular}{|l|l|}
\hline Component & Results \\
\hline PH & 7 \\
\hline Protein (g/L) & 46.5 \\
\hline Glucose (mmol/L) & 9.8 \\
\hline Total cholesterol (mmol/L) & 2.4 \\
\hline Triglycerides (mmol/L) & 20.82 \\
\hline $\begin{array}{l}\text { Ascitic fluid Lactic dehydroge- } \\
\text { nase (U/L) }\end{array}$ & 112 \\
\hline Ascitic fluid amylase (U/L) & 32 \\
\hline Adenosine deaminase (U/L) & 10 \\
\hline $\begin{array}{l}\text { Serum Ascites albumin gradi- } \\
\text { ent(SAAG) }\end{array}$ & $1.5 \mathrm{~g} /$ dL \\
\hline Cell count & White blood cells 2-3 \\
\hline \multicolumn{2}{|l|}{ Negative } \\
\hline Bacterial culture & Negative \\
\hline Gram stain & Negative \\
\hline Acid fast bacilli & Negative \\
\hline Mycobacterium tuberculosis PCR & Negative \\
\hline Tuberculosis culture & Negative \\
\hline Malignant cells & Ned cells 10 \\
\hline
\end{tabular}

PCR-polymerase chain reaction. 
He was managed with therapeutic paracentesis with albumin supplementation and advised to adhere to a low-fat diet. With that his symptoms were improved, and scrotal swelling was reduced. However, three months later he again presented with chylous ascites and three liters of fluid was removed. Since then, he did not develop ascites during the six months of follow up. He was referred to a gastro-enterology team with regular monitoring of liver functions to see the progression of liver disease and to monitor for a relapse of chylous ascites.

\section{Discussion}

The underlying pathophysiology of CA in liver cirrhosis is due to rupture of serosal lymphatic channels which are dilated because of excessive lymph flow secondary to elevated portal pressure (4).

The presenting features in the CA was systematically reviewed and showed that the most common symptoms were massive abdominal distension (81\%) followed by pain (15\%). CA was an incidental finding in $3 \%$, in that three cases were identified during the groin hernia repair (2). However, in this case the presenting complaint was scrotal swelling and the chylous ascites was an incidental finding which consequently ended up in the diagnosis of liver cirrhosis.

The gold standard investigation for chylous ascites is paracentesis with ascitic fluid analysis, and confirming the ascitic fluid triglyceride level above $200 \mathrm{mg} / \mathrm{dL}$. Other characteristics are cell count above 500 (lymphocytic predominance), total protein between 2.5 and $7.0 \mathrm{~g} / \mathrm{dL}$, SAAG above 1.1 $\mathrm{g} / \mathrm{dL}$, cholesterol ascites/serum ratio $<1$ and LDH between 110 and $200 \mathrm{IU} / \mathrm{L}$ (4). A SAAG above 1.1 $\mathrm{g} / \mathrm{dL}$ indicates that the CA is secondary to cirrhosis and values below that rules out portal hypertension and suggests other causes (5). In this case the ascitic fluid triglyceride level was $805.1 \mathrm{mg} / \mathrm{dL}$ Vol.33, No.1, July 2021 and liver cirrhosis was confirmed and the other possible causes were excluded. CT Abdomen is useful in identifying pathological intra-abdominal lymphnodes and masses. Lymphangiography and lymphoscintigraphy are useful in detecting abnormal retroperitoneal lymphnodes, leakage, fistulization and patency of lymphatic ducts $(1,4)$.

The main stay of the management of CA is treating the underlying condition. Other postulated treatment options are dietary modification, therapeutic paracentesis, pharmacological management and surgical interventions (5). A high-protein and low-fat diet with medium-chain triglycerides is recommended to reduce the formation of the lymph (5). Medical management with orlistat showed to reduce the triglyceride concentration $(1,4,5)$. Somatostatin and octreotide had been successfully used as well $(4,5)$.

In symptomatic patients therapeutic paracentesis will alleviate the symptoms. In patients with cirrhosis related CA, if it is refractory to treatment despite of normal liver function, transjugular intrahepatic portosystemic shunt (TIPS) could be considered to help reduce portal pressures (4). Here CA was managed with therapeutic paracentesis and dietary modification.

In general, the prognosis of non-surgical cases of CA is poorer than that of surgical ones. In the settings of CA due to cirrhosis, the degree of the liver disease is the most influential factor in determining the prognosis.

In conclusion, although chylous ascites is a relatively uncommon disorder, diagnosis can be readily made with simple tests. In the settings of liver cirrhosis, if malignancy considered unlikely, unnecessary invasive diagnostic procedures can be deferred. Treating the underlying condition is the main stay of the management and initial conservative approach with dietary modification and therapeutic paracentesis showed clinical improvement in chylous ascites related to liver cirrhosis. 


\section{Consent for publication}

Written informed consent was obtained from the patient.

\section{References}

1. Al-Busafi SA, Ghali P, Deschênes M and Wong P. Chylous Ascites: Evaluation and Management. ISRN Hepatol. 2014 Feb 3; 2014, http://dx.doi.org/10.1155/2014/240473

2. Steineman DC, Dindo D, Clavien P and Nocito A. Atraumatic Chylous Ascites: Systematic Review on Symptoms and Causes. J Am Coll Surg. 2011; 212 (5): 899-905. doi:10.1016/j. jamcollsurg.2011.01.010.
3. Cardenas Aand Chopra S. Chylous ascites. Am J Gastroenterol. 2002 Aug; 97(8): 1896-1900. doi: 10.1111/j.1572-0241.2002.05911.x.

4. Bhardwaj R, Vaziri H, Gautam A and et al. Chylous Ascites: A Review of Pathogenesis, Diagnosis and Treatment. J Clin Trans1 Hepatol. 2018; 6: 105-113. doi: 10.14218/ JCTH.2017.00035

5. Campbell S, Ghosh S and N. Williams N. Chylous ascites revisited - Old disease, New management. Proc R Coll Physicians Edinb. 2000; 30: 3-8. Available in: https://www.rcpe. ac.uk $>$ vol30_1.1P_0.pdf 